\title{
Lung cancer samples preserved in liquid medium: One step beyond cytology
}

\author{
Vânia Sammartino Mariano, $\mathrm{PhD}^{1 *}$ (1) | Letícia Ferro Leal, $\mathrm{PhD}^{1 *}$ | \\ Paula Roberta Aguiar Pastrez, MSc ${ }^{1}$ | Estela Maria Silva, MSc ${ }^{1}$ | \\ Rui Manuel Reis, PhD 1,2,3 | Adhemar Longatto-Filho, PhD, PMIAC1,2,3,4
}

${ }^{1}$ Barretos Cancer Hospital/Pio XII Foundation, Molecular Oncology Research Center, Brazil

${ }^{2}$ Research Institute of Life and Health Sciences (ICVS), University of Minho, Braga, Portugal

${ }^{3}$ ICVS/3B's - Associated Laboratory to the Government of Portugal, Braga/Guimarães, Portugal

${ }^{4}$ Medical Laboratory of Medical Investigation (LIM) 14, Department of Pathology, Faculty of Medicine, University of São Paulo, Brazil

Correspondence

Adhemar Longatto Filho, Laboratory of Medical Investigation (LIM) 14, Faculty of Medicine University São Paulo, Av. Dr. Arnaldo, 455 - Cerqueira César 1246-903, Sao Paulo, Brazil.

Email: longatto16@hotmail.com

\begin{abstract}
Lung cancer is one of the most common cancer types in men and women worldwide with a high mortality rate. World Health Organization (WHO) classification has accepted biopsy as the primary sample for lung cancer diagnosis, pathological classification and molecular testing for management of patients, yet, the use of alternative sampling procedures is highly encouraged. Bronchial cytological samples require a less invasive collection technique and may be suitable for pathological and molecular analysis and storage in liquid medium. Furthermore, the molecular analysis of bronchial cytological samples allows the detection of molecular biomarkers, which may be useful for the selection of molecular targeted therapies. Thus, the purpose of this review is to describe the usefulness of bronchial cytological samples preserved in liquid medium from lung cancer patients for pathological diagnosis and molecular investigation.
\end{abstract}

\section{KEYWORDS}

bronchial cytology, liquid medium, lung cancer, molecular biomarkers

\section{1 | INTRODUCTION}

Lung cancer is the major cause of cancer-related death among men and the second most common among women worldwide. ${ }^{1}$ The International Agency for Research on Cancer (IARC) reported that almost 1.6 million deaths in 2012 were due to lung cancer and estimated 1.8 million new cases for $2016 .{ }^{2}$ Only $15 \%$ of lung cancer cases are diagnosed at the initial stages of the disease, when the treatment is more effective, rendering a low overall survival rate of approximately $17 \% .^{3,4}$

In 2015, for the first time, the World Health Organization (WHO) classification proposed new criteria for the diagnosis of lung cancer based on small biopsies (bronchoscopic, needle or core biopsies) and cytology. For the collection of these biopsies, surgical resection is not required, resulting in a less invasive procedure for collection of speci-

*Vânia Sammartino Mariano and Letícia Ferro Leal contributed equally to this study. mens. ${ }^{5}$ These specimens are used for pathological classification, allowing the diagnosis of advanced stages of the disease, as well as for molecular testing to guide the treatment of patients, especially in inoperable cases. ${ }^{6,7}$ The major objective of biopsy is to establish the diagnosis and stage of disease and minimize the risk to the patient. ${ }^{8}$ Based on the high demand for these small specimens with limited tissue, the use of alternative samples is highly encouraged. ${ }^{8-10}$ Cytological smears and liquid-based cytology may be a less invasive option to avoid re-biopsy. This scenario was noted by the WHO in 2004, when the cytology was included for the first time as an acceptable diagnostic sample, and more recently by the Papanicolaou Society of Cytopathology Guidelines published for Standardized Terminology and Nomenclature for Respiratory Cytology. ${ }^{11}$ However, since then, the employment of cytological samples has been mostly limited to ancillary samples for diagnosis. Herein, we will focus in the main clinical and molecular aspects of lung cancer as well as the advantages of liquid-based cytology (LBC) for lung cancer diagnosis. 


\section{1 | Collecting bronchial samples}

Before showing the main aspects of lung cancer and the advantages of liquid cytology for the study of neoplastic or potentially neoplastic disease and the investigation of a variety of benign diseases, including opportunistic infections, ${ }^{12}$ we will briefly discuss the sampling procedure. The most common methods to obtain cytological specimens include fine-needle aspirates (FNAs) from lung (frequently coupled with core needle biopsies), bronchial brushings, bronchial washings, bronchoalveolar lavages and sputum, along other minimally invasive aspirations of distant, deep-seated or superficial metastatic lesions. ${ }^{13}$

Fine-needle aspirates (FNAs): as a collection method, the sensitivity and specificity for the diagnosis of lung cancer is high with an acceptable complication rate. ${ }^{14}$

Bronchial brushings: an useful option in endoscopically visible tumors, it can be performed before or after biopsy sampling, but it is advisable to be perform it before the bronchial biopsy to avoid contamination of the specimen with blood. ${ }^{15,16}$ For adequate representativeness of the suspect malignancy area, the brush should be forward/ reverse two or three times. ${ }^{17}$

Bronchial washing: it can also be taken before or after biopsy sampling. The exact volume to be recovered from this procedure has not been established; however, several studies recommend recovering as much fluid as possible after instilling $20-30 \mathrm{~mL}$ of sterile isotonic saline. ${ }^{15}$ The material is centrifuged and the sediment is used to prepare the smears or liquid-based preparations, which is then stained. ${ }^{17}$

Bronchoalveolar lavage (BAL): this technique increases the diagnostic yield in pulmonary peripheral lesions, and it is primarily used to diagnose infections and interstitial lung diseases. ${ }^{18}$ Unlike the other techniques, BAL has well-standardized guidelines. ${ }^{17}$

Sputum: it is not recommended as a suitable material for diagnosis of lung cancer due to its low sensitivity. ${ }^{19}$ In patients who are unable to undergo bronchoscopy or other minimally invasive procedure and for whom a diagnosis of malignancy is required, sputum may be helpful. It is recommended to repeat sputum sampling over several days for increased sensitivity. ${ }^{17,19}$

First, we would like to highlight that cytological samples are considered an important tool for the diagnosis of lung cancer due to their low cost and less invasive collection methods. ${ }^{17,20}$

\section{2 | Lung cancer: current aspects}

The pathogenesis of lung cancer is complex and it may occur due to a combination of genetic and environmental factors. ${ }^{21}$ Although smoking habits is the strongest factor linked to lung cancer, the incidence of the disease among non-smokers has increased. ${ }^{22}$ In addition to smoking, other factors are also related to lung cancer such as occupational exposure, previous lung disease and diet among others are attracting the attention of the physicians to patients who do not smoke. ${ }^{22-24}$ Based on this, we can suppose that additional factors might be the cause of the disease and they can function independently or in combination with the well-known factors. ${ }^{23,25}$
Regarding the histology, lung cancer is classified into two main groups: Small Cell Lung Cancer (SCLC) and Non-Small Cell Lung Cancer (NSCLC). ${ }^{26,27}$ For many years, this histological classification of lung cancer was sufficient for the management of lung cancer patients in routine practice. ${ }^{5}$

\subsection{Small Cell Lung Cancer (SCLC)}

Previously described as 'oat cell carcinoma' in a patient with asbestosis, SCLC exhibits neuroendocrine differentiation, strong association with smoking and genomic alterations enrolling genes with a key role in transcriptional regulation and chromatin modification. ${ }^{28,29}$ Patients with SCLC have carcinomas which display a high growth fraction, rapid doubling time and early establishment of widespread metastatic lesions and response to first-line chemotherapy. Nonetheless, SCLC patients experience relapse, and there is no approved targeted drug as a second line therapy for these tumors. ${ }^{30}$ However, this scenario may change since many promising advances with immune checkpoint inhibitors have emerged in the last few years. ${ }^{31,32}$

Genomic analyses have identified driver mutations in SCLC, leading to a better understanding about cellular features and molecular mechanisms involved in initiation, progression, metastasis and resistance. ${ }^{33}$ However, limited tumor tissue for research due to small diagnostic biopsies represents a significant barrier to progress in the research field, ${ }^{28,34}$ which can be circumvented using cytological samples.

Basically, lung carcinoma differentiation into SCLC and NSCLC subsets is important for the clinical management of the patients. The first step for the diagnosis is the observation of cytological features from tumor samples. The diagnosis of SCLC can be achieved through cytomorphology of FNA prepared using ThinPrep and conventional smears. ${ }^{35}$ Indeed, the LBC of sputum specimens from 101 patients with lung cancer exhibited a significantly higher sensitivity for SCLC diagnosis $(P<.05)$ than conventional smear, suggesting the LBC may be easily and widely applied for lung cancer diagnosis. ${ }^{36}$ The diagnostic value of LBC was also shown using 4,380 brushing specimens from lung cancer patients. The accuracy was $75.6 \%$ and, compared with histopathology-gold standard, the LBC allowed lung cancer subtyping into squamous cell carcinoma, adenocarcinoma and small cell carcinoma with accuracy rates of 95.6\% (351/367), 95.6\% (351/367) and $100 \%$ (367/367), respectively $(P<.001)$, with the highest value for SCLC. These results emphasize that LBC is an effective tool for the diagnosis and subtyping of lung cancer. ${ }^{37}$ and should be better exploited.

\section{4 | Non-Small Cell Lung Cancer (NSCLC)}

The NSCLC group can be further subdivided into three major cell types: adenocarcinoma, squamous cell carcinoma and large cell carcinoma. Adenocarcinoma is the most common histological type and generally arises in the distal airways. ${ }^{38}$ Squamous cell carcinoma usually arises in the proximal airways and in the hilum or close to it. ${ }^{38,39}$ Large cell carcinoma is diagnosed by exclusion, when the tumor cells do not present glandular or squamous appearance and present with distinctive 
histological elements, giant cells and clear cells. ${ }^{39}$ Among all cases of lung cancer, approximately $80 \%-85 \%$ are diagnosed as NSCLC, and among all NSCLC cases, almost $70 \%$ are locally advanced or metastatic. ${ }^{40}$ For metastatic NSCLC cases, chemotherapy, targeted therapy and/or radiation therapy are not effective for disease cure and they can only extend survival and palliate the symptoms.

In general, the diagnosis of lung cancer involves three important steps: (I) identification and classification of malignancy, (II) immunohistochemistry to predict the likely NSCLC subtype and (III) molecular testing, mainly in advanced adenocarcinoma to investigate oncogenic driver mutations. ${ }^{17}$ The evidence of therapeutically relevant driver mutations in subsets of NSCLC and the emerging drugs as targeted therapies for some subtypes of NSCLC have rendered the classification of NSCLC subtypes clinically mandatory. ${ }^{5}$

\section{5 | Lung cancer: molecular landscape}

\subsection{1 | EGFR}

Mutations in the epidermal growth factor receptor (EGFR) gene activate this receptor, which leads to the activation of intracellular signaling pathways involved in cell proliferation, differentiation and cell cycle, triggering neoplastic progression. The most common mutations are located between exons 19 and 21 and they are frequently observed in some types of lung cancers especially adenocarcinomas. Among NSCLC, EGFR hotspot mutations are found in approximately 10\%-15\% of all tumors, being more common in female patients, non-smokers and Asian patients, in which the frequency of these mutations is improved. ${ }^{41,42}$ The presence of EGFR mutations is related to the prognosis of NSCLC patients, sensitivity and improved response to tyrosine kinase inhibitors (TKIs) such as erlotinib and gefitinib. ${ }^{43-47}$

\subsection{2 | KRAS}

Mutations in the kirsten rat sarcoma viral oncogene homolog (KRAS) oncogene have been associated with several malignancies including as pancreatic cancer, colorectal cancer and lung cancer. ${ }^{48-50}$ KRAS mutations occur in approximately $20 \%$ of NSCLC patients and are commonly located at codons 12 and 13 of the gene. These mutations are associated with smoking habits, have a worse prognosis and are more common in the NSCLC subtype. ${ }^{38,51,52}$ Patients harboring KRAS, unlike EGFR-mutated patients, do not benefit from TKIs, probably because $K R A S$ itself is difficult to inhibit, and the effectiveness of agents targeting KRAS effectors have been blocked by the activation of offsetting pathways that limit their efficiency. ${ }^{53,54}$

\subsection{3 | EML4-ALK}

Anaplastic lymphoma kinase ( $A L K)$ is a tyrosine kinase receptor translocations of which trigger an oncogenic process in NSCLC tumors. ${ }^{55}$ The echinoderm microtubule associated protein like 4 (EML4) gene is located near to ALK gene. ${ }^{55}$ An inversion in the short arm of chromosome 2 results in a fusion gene comprising parts of the ALK and EML4 genes. The protein encoded by this gene-fusion gene is highly oncogenic and associated with NSCLC pathogenesis in a subgroup of patients. ${ }^{55}$ ALK-EML4 translocations and EGFR and KRAS mutations are mutually exclusive. ${ }^{56,57}$ The oral inhibitor of the ALK tyrosine kinase domain, crizotinib, was effective in decreasing in vitro cell proliferation and to improve overall and disease-free survival in NSCLC patients harboring ALK-EML4 translocations. ${ }^{58,59}$ However, the frequency of this alteration in patients with NSCLC is low, approximately $3 \%-7 \% .55-57,60$

\section{6 | Molecular biomarkers in body fluids}

In the last few years, many studies have emerged to investigate lung cancer biomarkers, which have been defined for prognostic purposes, diagnosis and early detection of the disease. The detection of biomarkers can help to define tumor stage, recognition of recurrence, and to support disease and treatment monitoring. ${ }^{61}$ These biomarkers may be proteins, RNA molecules, miRNAs, methylated DNAs and, more recently, circulating tumor cells. ${ }^{62}$ Tumor biomarkers are secreted by the neoplastic tissue into body fluids and help to distinguish abnormal from normal conditions. ${ }^{50,63}$ Body fluids are generally easily obtained and may be routinely collected for laboratory testing. Among body fluids in lung cancer patients, bronchial washes are obtained in a volume sufficient to allow its use in molecular biomarker identification.

\subsection{1 | Molecular biomarkers and clinical relevance for lung cancer patients}

In routine practice, patients with advanced adenocarcinomas are currently tested for EGFR mutations and ALK aberrations. ${ }^{5}$ Since 2009, several clinical trials have reported better response rates and increased progression-free survival in patients with advanced NSCLC with mutations in EGFR gene who received TKIs compared with conventional therapy. ${ }^{64-66}$ Since most patients with early-stage lung cancer will eventually experienced relapse and disease progression, the College of American Pathologists (CAP), the International Association for the Study of Lung Cancer (IASLC) and the Association for Molecular Pathology (AMP) have developed a guideline encouraging EGFR and $A L K$ testing for lung cancer at the time of diagnosis for patients presenting with advanced disease stage to guide clinical management with targeted therapies. ${ }^{47,59,67}$

ALK-EML4 translocations and EGFR and KRAS mutations are mutually exclusive. ${ }^{33,34}$ Thus, when EGFR and KRAS mutations are absent, the detection of ALK-EML4 translocations is crucial for a favorable response to crizotinib. ${ }^{68}$ Until now, the only FDA-approved laboratory test to detect ALK-EML4 translocations is fluorescence in situ hybridization (FISH), which allows direct visualization of multiple changes in chromosomes and in the number of gene copies. ${ }^{69}$ However, new technologies have emerged, such as NanoString, to detect this alteration, including other gene fusions such as fusion comprising the RET and ROS1 genes. $^{70}$

Different from EGFR-mutated patients, those harboring KRAS mutations do not benefit from TKIs. The main reason for this problem is probably because KRAS itself is difficult to inhibit, and the effectiveness of agents targeting KRAS effectors has been blocked by the activation of offsetting pathways limiting their efficiency. ${ }^{53,54}$ To date, there is no effective targeted therapy for patients harboring KRAS mutations. ${ }^{71}$ Trametinib acts downstream of KRAS and suppresses the 


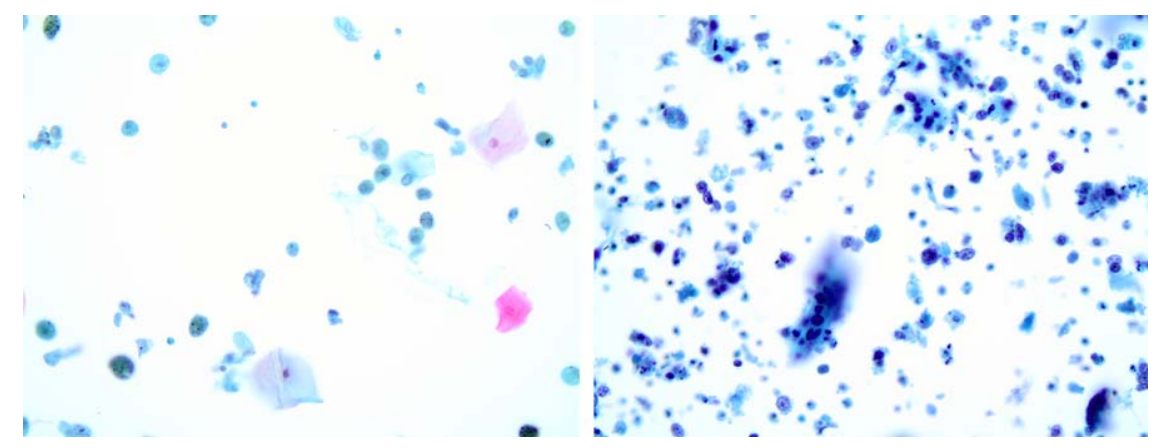

FIGURE 1 The Papanicolaou stain allows the cytologic analyses of squamous cell carcinoma features $(40 \times)$ from two patients [Color figure can be viewed at wileyonlinelibrary.com]

MAPK signaling; however, it was recently demonstrated that trametinib provokes a compensatory response mediated by the fibroblast growth factor receptor 1 (FGFR1), leading to adaptive drug resistance and FGFR1 inhibition increased sensitivity to trametinib. These data paved the way for a combinatorial approach to treat KRAS-mutant lung cancer and open opportunities for effective treatment for these patients. $^{72}$

\section{7 | Liquid medium beyond cytology}

The concept of personalized medicine of lung cancer is based on the therapeutic decisions driven by the specific histology and genetic features of patient's tumor. However, the biopsy techniques traditionally performed provide limited specimens that usually are insufficient for all tests and frequently require re-biopsy the performance of which depends on the patients clinical situation. ${ }^{5}$

In this sense, cytological samples are an attractive tool to help in the management of patients with lung cancer because it enables genomic and proteomic assays beyond cellular analysis, with the advantage of being enriched in tumor cells and not formalinfixed. ${ }^{20,73,74}$

Thus, the maintenance of cytologic bronchial material in liquid medium, initially used for gynecological issue (LBC), represents an useful method. This is, especially true in cases where there is no option to immediately prepare the smear. These liquid-based methods, preserve the morphology of cells at room temperature for a long time until laboratorial processing can occur (Figure 1).

\subsection{1 | Assessing molecular biomarkers in cytological samples}

Among molecular laboratory tests for assessing EGFR mutations in cytological samples, PCR-based techniques can be highlighted including direct sequencing, real-time PCR, pyrosequencing, fragment length analysis and high resolution melting analysis, amplification-refractory mutation system, peptide nucleic acid-locked nucleic acid, low denaturation temperature co-amplification and next-generation sequencing (NGS). ${ }^{20} \mathrm{FISH}$ (fluorescence in situ hybridization), employed for the detection of ALK rearrangements, has been shown to be significantly more sensitive to detect cancer in brushed bronchial specimens than conventional cytology, and it allows the detection of tumors in early stages and those tumours peripherally located. In addition, there are reports describing immunocytochemistry (ICQ) applying anti-ALK antibodies as a faster and low-cost alternative to FISH assays in cytological samples. $^{73}$

Beyond that, differentially expressed proteins can be easily detected using specific antibodies in ICQ technique, and the detection of these proteins reflects signaling pathways activation or inactivation, which contributes for the identification of molecular aspects of lung cancer in cytological samples. ${ }^{75}$

Likewise, flow cytometry is widely used to quantify cells and inflammatory molecules. This technique may be carried out using cytology samples from BAL specimens. Several studies have shown that flow cytometry is useful to differentiate CD4+, CD8+ and CD56 + lymphocytes, which are present in BAL specimens from both in lung cancer and in pulmonary diseases such as asthma. ${ }^{76}$ BAL provides non-cellular components of the fluid covering the respiratory epithelium and allows the quantification of cytokines (e.g., IL-6 and IL-1 b) employing cytometry beads-assay. ${ }^{77,78}$

Another approach that highly fits employing cytological samples is next-generation sequencing (NGS), which uses a simple platform to assess several variations such as single-nucleotide polymorphisms (SNPs), insertions and deletions, as well as gene amplifications and rearrangements ${ }^{73,79}$ Very recently, a complete workflow for detection of low frequency somatic mutations from cell-free DNA was developed for a NGS platform. Basically, the workflow consists of cell-free DNA isolation, library preparation, sequencing and a user-friendly data analysis. This panel comprises $>150$ hotspots variants across 11 crucial genes for NSCLC, such as EGFR, KRAS, TP53 and MET. The workflow was initially tested on samples from matched tumor FFPE and plasma collected from NSCLC patients. According to the manufacturer, results indicated high sensitivity and significant overlapping of variants detected in the FFPE and plasma samples with a limit of detection of $0.1 \%$ of somatic mutations. ${ }^{80}$ Another platform has been developed for liquid biopsies, specially focused on EGFR mutation testing in plasma samples from NSCLC patients, although different biopsies specimens have also been used such as core-needle and cytology. ${ }^{81}$ These approaches have emerged as useful for the monitoring of treatment and disease progression in body fluids from NSCLC patients. In this context, liquid cytology might also be potentially used as a specimen 
for liquid biopsy, which is a less invasive method, easily obtained and likely to be better tolerated than rebiopsy for patients. Another possible use of cytology is the identification of causative agents and management of patients with infectious diseases. ${ }^{8,74}$ Because the lung is the largest epithelial surface in the body, it constitutes the major portal for the entry of microorganisms such as viruses, bacteria and fungal organisms. ${ }^{82}$ The diagnosis of microorganisms is based particularly on molecular methods of nucleic acid analysis and microarrays, and classified as amplified, unamplified. ${ }^{83}$ In clinical practice, PCR is the most common method for the detection of microorganisms such as Streptococcus pneumonia, Mycoplasma pneumonia and Staphylococcus aureus, among others. Currently, real-time PCR has been widely used because it offers a lower risk of contamination, rapid turn-around and its sensitivity allows the detection of infectious agents found in low concentrations in cytological samples. More recently, studies have shown the utility of BAL for investigation of respiratory microbiota and metabolic profiles from HIV-infected individuals ${ }^{84}$ and patients with cystic fibro$\mathrm{sis}^{85}$ these conditions being contributor conditions for lung cancer development. So far, cytological samples have not been employed for microbiota investigation in the pulmonary oncology field; however, there are predictable data for attracting the attention to a high-risk population for developing lung neoplasms. Thus, these findings reinforce the importance of cytological samples for the lung cancer field.

\section{2 | CONCLUDING REMARKS}

The current era of personalized medicine using mutational screening for clinical management of lung cancer patients has brought major advances in lung cancer therapy and it has allowed the identification of patients who could benefit from targeted therapies. Cytology samples have become an attractive tool to be employed in association with the histology approach.

\section{DISCLOSURE OF GRANTS OR OTHER FUNDING}

Rui Manuel Reis and Adhemar Longatto-Filho have a Brazilian National Counsel of Technological and Scientific Development (CNPq) Produtivity scholarship.

\section{CONFLICT OF INTEREST}

The authors declare no conflict of interest.

\section{REFERENCES}

[1] Reck M. What future opportunities may immuno-oncology provide for improving the treatment of patients with lung cancer? Ann Oncol. 2012;23:viii28-viii34.

[2] Ferlay J, Soerjomataram I, Dikshit R, et al. Cancer incidence and mortality worldwide: sources, methods and major patterns in GLOBOCAN 2012. Int J Cancer 2015;136:E359-E386.

[3] Jemal A, Siegel R, Xu J, Ward E. Cancer statistics, 2010. CA: A Cancer J Clin. 2010;60:277-300.
[4] Sung WW, Lee H. The role of interleukin-10 in the progression of human papillomavirus-associated lung carcinoma. Oncoimmunology 2013;2:e25854

[5] Travis WD, Brambilla E, Nicholson AG, et al. The 2015 World Health Organization classification of lung tumors: impact of genetic, clinical and radiologic advances since the 2004 classification. J Thorac Oncol. 2015;10:1243-1260.

[6] Lindeman NI, Cagle PT, Beasley MB, et al. Molecular testing guideline for selection of lung cancer patients for EGFR and ALK tyrosine kinase inhibitors: guideline from the College of American Pathologists, International Association for the Study of Lung Cancer, and Association for Molecular Pathology. J Mol Diagn. 2013;15:415-453.

[7] Leighl NB, Rekhtman N, Biermann WA, et al. Molecular testing for selection of patients with lung cancer for epidermal growth factor receptor and anaplastic lymphoma kinase tyrosine kinase inhibitors: American Society of Clinical Oncology endorsement of the College of American Pathologists/International Association for the study of lung cancer/association for molecular pathology guideline. J Clin Oncol. 2014;32:3673-3679.

[8] Michael CW, Hoda RS, Saqi A, et al. Committee I: indications for pulmonary cytology sampling methods. Diagn Cytopathol. 2016;44: 1010-1023.

[9] Oktay MH, Adler E, Hakima L, et al. The Application of Molecular Diagnostics to Stained Cytology Smears. The Journal of Molecular Diagnostics: JMD 2016;18:407-415.

[10] Rossi ED, Bizzarro T, Longatto-Filho A, Gerhard R, Schmitt F. The diagnostic and prognostic role of liquid-based cytology: are we ready to monitor therapy and resistance? Expert Rev Anticancer Ther. 2015;15:911-921.

[11] Layfield LJ, Baloch Z, Elsheikh T, et al. Standardized terminology and nomenclature for respiratory cytology: the Papanicolaou Society of Cytopathology guidelines. Diagn Cytopathol. 2016;44:399-409.

[12] Guidelines of the Papanicolaou Society of Cytopathology for the examination of cytologic specimens obtained from the respiratory tract. Papanicolaou Society of Cytopathology Task Force on Standards of Practice. Diagn Cytopathol. 1999;21(1):61-69.

[13] da Cunha Santos G. Standardizing preanalytical variables for molecular cytopathology. Cancer Cytopathol. 2013;121:341-343.

[14] Yao X, Gomes MM, Tsao MS, Allen CJ, Geddie W, Sekhon H. Fineneedle aspiration biopsy versus core-needle biopsy in diagnosing lung cancer: a systematic review. Curr Oncol. 2012;19:e16-e27.

[15] van der Drift MA, van der Wilt GJ, Thunnissen FB, Janssen JP. A prospective study of the timing and cost-effectiveness of bronchial washing during bronchoscopy for pulmonary malignant tumors. Chest. 2005;128:394-400.

[16] Fernandez-Villar A, Gonzalez A, Leiro V, et al. [Effect of different bronchial washing sequences on diagnostic yield in endoscopically visible lung cancer]. Archiv Bronconeumol. 2006;42:278-282.

[17] Thunnissen E, Kerr KM, Herth FJ, et al. The challenge of NSCLC diagnosis and predictive analysis on small samples. Practical approach of a working group. Lung Cancer 2012;76:1-18.

[18] Pirozynski M. Bronchoalveolar lavage in the diagnosis of peripheral, primary lung cancer. Chest 1992;102:372-374.

[19] Thunnissen FB. Sputum examination for early detection of lung cancer. J Clin Pathol. 2003;56:805-810.

[20] Schmitt FC, Longatto-Filho A, Valent A, Vielh P. Molecular techniques in cytopathology practice. J Clin Pathol. 2008;61:258-267.

[21] Sarchianaki E, Derdas SP, Ntaoukakis M, et al. Detection and genotype analysis of human papillomavirus in Non-Small Cell Lung Cancer patients. Tumour Biol. 2014;35:3203-3209. 
[22] Sagerup CM, Nymoen DA, Halvorsen AR, et al. Human papilloma virus detection and typing in 334 lung cancer patients. Acta Oncol. 2014.

[23] Thun MJ, Henley SJ, Calle EE. Tobacco use and cancer: an epidemiologic perspective for geneticists. Oncogene. 2002;21:73077325.

[24] Sun S, Schiller JH, Gazdar AF. Lung cancer in never smokers-a different disease. Nat Rev Cancer. 2007;7:778-790.

[25] Brownson RC, Alavanja MC, Caporaso N, Simoes EJ, Chang JC. Epidemiology and prevention of lung cancer in nonsmokers. Epidemiol Rev. 1998;20:218-236.

[26] Zheng M. Classification and pathology of lung cancer. Surg Oncol Clin North Am. 2016;25:447-468.

[27] Duan MC, Zhong XN, Liu GN, Wei JR. The Treg/Th17 paradigm in lung cancer. J Immunol Res. 2014;2014:730380.

[28] Santarpia M, Daffina MG, Karachaliou N, et al. Targeted drugs in small-cell lung cancer. Transl Lung Cancer Res. 2016;5:51-70.

[29] Koinis F, Kotsakis A, Georgoulias V. Small Cell Lung Cancer (SCLC): no treatment advances in recent years. Transl Lung Cancer Res. 2016;5:39-50.

[30] Horn L, Reck M, Spigel DR. The future of immunotherapy in the treatment of Small Cell Lung Cancer. Oncologist. 2016;21: 910-921.

[31] Sharp A, Bhosle J, Abdelraouf F, et al. Development of molecularly targeted agents and immunotherapies in Small Cell Lung Cancer. Eur J Cancer. 2016;60:26-39.

[32] Reck M, Luft A, Szczesna A, et al. Phase III randomized trial of ipilimumab plus etoposide and platinum versus placebo plus etoposide and platinum in extensive-stage Small-Cell Lung Cancer. J Clin Oncol. 2016

[33] Semenova EA, Nagel R, Berns A. Origins, genetic landscape, and emerging therapies of Small Cell Lung Cancer. Genes Dev. 2015;29: 1447-1462.

[34] Byers LA, Rudin CM. Small Cell Lung Cancer: where do we go from here? Cancer. 2015;121:664-672.

[35] Bavikatty NR, Michael CW. Cytologic features of small-cell carcinoma on ThinPrep. Diagn Cytopathol. 2003;29:8-12.

[36] Wu GP, Wang EH, Li JH, Fu ZM, Han S. Clinical application of the liquid-based cytological test in cytological screening of sputum for the diagnosis of lung cancer. Respirology. 2009;14:124-128.

[37] Zhao H, Guo H, Zhang C, et al. [Value of liquid-based cytology of brushing specimens obtained via fiberoptic bronchoscopy for the diagnosis of lung cancer]. Zhonghua Zhong Liu Za Zhi [Chin J Oncol.] 2015;37:431-435

[38] Chen Z, Fillmore CM, Hammerman PS, Kim CF, Wong KK. NonSmall-Cell Lung Cancers: a heterogeneous set of diseases. Nat Rev Cancer. 2014:14:535-546.

[39] Younes R, Buzaid AC, Katz A. Câncer de Pulmão: Tratamento Multidisciplinar. São Paulo: Dendrix Edição e Design; 2008.

[40] Molina JR, Yang P, Cassivi SD, Schild SE, Adjei AA. Non-Small Cell Lung Cancer: epidemiology, risk factors, treatment, and survivorship. Mayo Clin Proc. 2008;83:584-594.

[41] Sharma SV, Bell DW, Settleman J, Haber DA. Epidermal growth factor receptor mutations in lung cancer. Nat Rev Cancer. 2007;7: 169-181.

[42] Krishnan VG, Ebert PJ, Ting JC, et al. Whole-genome sequencing of Asian lung cancers: second-hand smoke unlikely to be responsible for higher incidence of lung cancer among Asian never-smokers. Cancer Res. 2014;74:6071-6081.
[43] Lynch TJ, Bell DW, Sordella R, et al. Activating mutations in the epidermal growth factor receptor underlying responsiveness of Non-Small-Cell Lung Cancer to gefitinib. N Engl J Med. 2004;350: 2129-2139.

[44] Paez JG, Janne PA, Lee JC, et al. EGFR mutations in lung cancer: correlation with clinical response to gefitinib therapy. Science. 2004; 304:1497-1500.

[45] Pao W, Miller V, Zakowski M, et al. EGF receptor gene mutations are common in lung cancers from "never smokers" and are associated with sensitivity of tumors to gefitinib and erlotinib. Proc Nat Acad Sci USA. 2004:101:13306-13311.

[46] Pao W, Wang TY, Riely GJ, et al. KRAS mutations and primary resistance of lung adenocarcinomas to gefitinib or erlotinib. PLoS Med. 2005;2:e17.

[47] Piotrowska Z, Sequist LV. Epidermal growth factor receptor-mutant lung cancer: new drugs, new resistance mechanisms, and future treatment options. Cancer J. 2015;21:371-377.

[48] Carter GC, Landsman-Blumberg PB, Johnson BH, et al. KRAS testing of patients with metastatic colorectal cancer in a communitybased oncology setting: a retrospective database analysis. J Exp Clin Cancer Res: CR 2015;34:29.

[49] Collins MA, Bednar F, Zhang Y, et al. Oncogenic KRAS is required for both the initiation and maintenance of pancreatic cancer in mice. J Clin Investig. 2012;122:639-653.

[50] Cho JY, Sung HJ. Proteomic approaches in lung cancer biomarker development. Expert Rev Proteomics. 2009;6:27-42.

[51] Cardarella S, Ortiz TM, Joshi VA, et al. The introduction of systematic genomic testing for patients with non-small-cell lung cancer. J Thorac Oncol. 2012;7:1767-1774.

[52] Shepherd FA, Domerg C, Hainaut P, et al. Pooled analysis of the prognostic and predictive effects of KRAS mutation status and KRAS mutation subtype in early-stage resected Non-Small-Cell Lung Cancer in four trials of adjuvant chemotherapy. J Clin Oncol. 2013;31:2173-2181.

[53] Linardou H, Dahabreh IJ, Kanaloupiti D, et al. Assessment of somatic k-RAS mutations as a mechanism associated with resistance to EGFR-targeted agents: a systematic review and meta-analysis of studies in advanced Non-Small-Cell Lung Cancer and metastatic colorectal cancer. Lancet Oncol. 2008;9:962-972.

[54] Cox AD, Fesik SW, Kimmelman AC, Luo J, Der CJ. Drugging the undruggable RAS: mission possible? Nat Rev Drug Discov. 2014;13: 828-851.

[55] Soda M, Choi YL, Enomoto M, et al. Identification of the transforming EML4-ALK fusion gene in Non-Small-Cell Lung Cancer. Nature. 2007;448:561-566.

[56] Shaw AT, Yeap BY, Mino-Kenudson M, et al. Clinical features and outcome of patients with Non-Small-Cell Lung Cancer who harbor EML4-ALK. J Clin Oncol. 2009;27:4247-4253.

[57] Rodig SJ, Mino-Kenudson M, Dacic S, et al. Unique clinicopathologic features characterize ALK-rearranged lung adenocarcinoma in the western population. Clin Cancer Res. 2009;15:5216-5223.

[58] Kwak EL, Bang YJ, Camidge DR, et al. Anaplastic lymphoma kinase inhibition in Non-Small-Cell Lung Cancer. N Engl J Med. 2010;363: 1693-1703.

[59] Solomon BJ, Mok T, Kim DW, et al. First-line crizotinib versus chemotherapy in ALK-positive lung cancer. N Engl J Med. 2014;371: 2167-2177.

[60] Waggott D, Chu K, Yin S, et al. NanoStringNorm: an extensible R package for the pre-processing of NanoString mRNA and miRNA data. Bioinformatics. 2012;28:1546-1548. 
[61] I H, Cho JY. Lung cancer biomarkers. Adv Clin Chem. 2015;72:107170.

[62] Hamilton G, Rath B, Ulsperger E. A review of the role of surgery for Small Cell Lung Cancer and the potential prognostic value of enumeration of circulating tumor cells. Eur J Surg Oncol. 2016.

[63] Sung HJ, Cho JY. Biomarkers for the lung cancer diagnosis and their advances in proteomics. BMB Rep. 2008;41:615-625.

[64] Mok TS, Wu YL, Thongprasert S, et al. Gefitinib or carboplatinpaclitaxel in pulmonary adenocarcinoma. N Engl J Med. 2009;361: 947-957.

[65] Mitsudomi T, Morita S, Yatabe Y, et al. Gefitinib versus cisplatin plus docetaxel in patients with non-small-cell lung cancer harbouring mutations of the epidermal growth factor receptor (WJTOG3405): an open label, randomised phase 3 trial. Lancet Oncol. 2010;11:121-128.

[66] Maemondo M, Inoue A, Kobayashi K, et al. Gefitinib or chemotherapy for Non-Small-Cell Lung Cancer with mutated EGFR. N Engl J Med. 2010;362:2380-2388.

[67] Lindeman NI, Cagle PT, Beasley MB, et al. Molecular testing guideline for selection of lung cancer patients for EGFR and ALK tyrosine kinase inhibitors: guideline from the College of American Pathologists, International Association for the Study of Lung Cancer, and Association for Molecular Pathology. J Thorac Oncol. 2013;8:823-859.

[68] Shaw AT, Kim DW, Nakagawa K, et al. Crizotinib versus chemotherapy in advanced ALK-positive lung cancer. N Engl J Med. 2013;368: 2385-2394.

[69] Cruz-Rico G, Aviles-Salas A, Segura-Gonzalez M, et al. Diagnosis of EML4-ALK translocation with FISH, immunohistochemistry, and real-time polymerase chain reaction in patients with Non-Small Cell Lung Cancer. Am J Clin Oncol. 2015.

[70] Lira ME, Choi YL, Lim SM, et al. A single-tube multiplexed assay for detecting ALK, ROS1, and RET fusions in lung cancer. J Mol Diagn. 2014;16:229-243.

[71] Kumar M, Ernani V, Owonikoko TK. Biomarkers and targeted systemic therapies in advanced Non-Small Cell Lung Cancer. Mol Aspects Med. 2015;45:55-66.

[72] Manchado E, Weissmueller S, Morris JPt, et al. A combinatorial strategy for treating KRAS-mutant lung cancer. Nature. 2016;534: 647-651.

[73] Roy-Chowdhuri S, Aisner DL, Allen TC, et al. Biomarker testing in lung carcinoma cytology specimens: a perspective from members of the pulmonary pathology society. Archiv Pathol Lab Med. 2016.

[74] Layfield LJ, Roy-Chowdhuri S, Baloch Z, et al. Utilization of ancillary studies in the cytologic diagnosis of respiratory lesions: the Papanicolaou Society of Cytopathology consensus recommendations for respiratory cytology. Diagn Cytopathol. 2016;44:1000-1009.
[75] Sholl LM. Protein correlates of molecular alterations in lung adenocarcinoma: immunohistochemistry as a surrogate for molecular analysis. Semin Diagn Pathol. 2015;32:325-333.

[76] Mortaz E, Gudarzi H, Tabarsi P, et al. Flow cytometry applications in the study of immunological lung disorders. Iranian J Allergy Asthma Immunol. 2015;14:12-18.

[77] Cross CE, van der Vliet A, O'Neill CA, Louie S, Halliwell B. Oxidants, antioxidants, and respiratory tract lining fluids. Environ Health Perspect. 1994;102: 185-191.

[78] Crohns M, Saarelainen S, Laine S, et al. Cytokines in bronchoalveolar lavage fluid and serum of lung cancer patients during radiotherapy-association of interleukin-8 and VEGF with survival. Cytokine. 2010;50:30-36.

[79] Buttitta F, Felicioni L, Del Grammastro M, et al. Effective assessment of egfr mutation status in bronchoalveolar lavage and pleural fluids by next-generation sequencing. Clin Cancer Res. 2013;19: 691-698.

[80] Gu J, Brinza D, Mongan A, et al. Complete workflow for detection of low frequency somatic mutations from cell-free DNA using lon Torrent platforms. [Poster]. In press, 2016.

[81] Karlovich C, Goldman JW, Sun JM, et al. Assessment of EGFR mutation status in matched plasma and tumor tissue of NSCLC patients from a Phase I study of rociletinib (CO-1686). Clin Cancer Res. 2016;22:2386-2395.

[82] Masten BJ. Initiation of lung immunity: the afferent limb and the role of dendritic cells. Semin Respir Crit Care Med. 2004;25:11-20.

[83] Canberk S, Longatto-Filho A, Schmitt F. Molecular diagnosis of infectious diseases using cytological specimens. Diagn Cytopathol. 2016;44:156-164.

[84] Cribbs SK, Uppal K, Li S, et al. Correlation of the lung microbiota with metabolic profiles in bronchoalveolar lavage fluid in HIV infection. Microbiome. 2016;4:3.

[85] Hogan DA, Willger SD, Dolben EL, et al. Analysis of lung microbiota in bronchoalveolar lavage, protected brush and sputum samples from subjects with mild-to-moderate cystic fibrosis lung disease. PloS One 2016;11:e0149998.

How to cite this article: Mariano VS, Leal LF, Roberta Aguiar Pastrez $\mathrm{P}$, et al. Lung cancer samples preserved in liquid medium: One step beyond cytology. Diagnostic Cytopathology. 2017;45:915-921. https://doi.org/10.1002/dc.23743 